\title{
Effects of Gamma Irradiation, Modified Atmosphere Packaging, and Delay of Irradiation on Quality of Fresh-cut Iceberg Lettuce
}

\author{
Xuetong Fan ${ }^{1}$ and Kimberly J.B. Sokorai \\ U.S. Department of Agriculture, Agricultural Research Service, Eastern \\ Regional Research Center, 600 E. Mermaid Lane, Wyndmoor, PA 19038
}

Additional index words. injury, fresh-cut, browning, texture, sensory, gamma radiation

\begin{abstract}
This study was conducted to investigate the effect of modified atmosphere packaging (MAP) and delay of irradiation application on the quality of cut Iceberg lettuce. Overall visual quality and tissue browning of cut lettuce were evaluated using a scale of 9 to 1 , whereas texture was analyzed instrumentally during 14 days of storage at $4{ }^{\circ} \mathrm{C}$. Results showed that irradiation ( 0.5 and $1.0 \mathrm{kGy})$ of cut lettuce induced tissue browning when stored in air; however, when cut lettuce was stored in MAP, irradiated lettuce had better appearance than the non-irradiated ones as a result of lower $\mathrm{O}_{2}$ levels in the packages of irradiated samples compared with the levels in control packages. In general, irradiation at doses of 0.5 and $1.0 \mathrm{kGy}$ did not affect firmness of the lettuce. After 14 days of MAP storage, overall visual quality of non-irradiated samples had a score of $\approx 4$, a score below the limit of sales appeal, whereas the two irradiated samples had scores of 6.5 to 7.9 , indicating the irradiated samples had a fair to good quality. Delaying irradiation by 1 day after preparation of cut lettuce did not significantly $(P>0.05)$ affect cut edge browning, surface browning, or overall visual quality compared with lettuce irradiated immediately after preparation. Our results suggest that MAP is essential to minimize quality deterioration caused by irradiation.
\end{abstract}

The recent outbreaks of foodborne illness associated with leafy greens highlights the limitations of chemical sanitizers that are currently used by the produce industry. A "kill" step is needed to ensure the safety of such produce. Ionizing radiation is known to effectively eliminate human pathogens such as Escherichia coli $\mathrm{O} 157: \mathrm{H} 7$ on fresh produce (Niemira and Fan, 2006). In 2008, ionizing irradiation was approved by the U.S. Food and Drug Administration for use on fresh Iceberg lettuce and spinach to enhance microbial safety at doses not exceeding $4 \mathrm{kGy}$. Either whole lettuce or fresh-cut lettuce is allowed to be treated with radiation. Irradiation is ideally applied after packaging to prevent post-process contamination. However, the commercial application of irradiation to fresh produce is still limited partially as a result

\footnotetext{
Received for publication 22 Oct. 2010. Accepted for publication 13 Dec. 2010.

This study was conducted through a collaborative research agreement with Tanimura and Antle Produce Co. (Agreement No. 58-1935-8-882N). We thank Dr. John Phillips for statistical analysis; and Wenqiang Guan, Tyreek Anderson, and Matthew Moore for technical assistance.

Mention of trade names or commercial products in this article is solely for the purpose of providing specific information and does not imply recommendation or endorsement by the U.S. Department of Agriculture.

${ }^{1}$ To whom reprint requests should be addressed. e-mail xuetong.fan@ars.usda.gov.
}

of concerns about possible damage to sensory and nutritional quality.

Fresh-cut Iceberg lettuce for food service consists predominantly of shredded lettuce. In the retail market, fresh-cut Iceberg lettuce is often mixed with other fresh-cut vegetables for use as pre-packaged salads. Processing of fresh-cut lettuce typically involves removal of outer leaves, shredding, washing, sanitizing, rinsing, and dewatering before MAP using film bags (Barth et al., 2009). Fresh-cut lettuce has a relatively short shelf life even when stored in MAP, mostly as a result of the development of tissue browning and development of off-flavor/off-odor (Hodges and Toivonen, 2008).

Hagenmaier and Baker (1997) studied the effect of irradiation on cut Iceberg lettuce under MAP and found irradiation at 0.15 to $0.5 \mathrm{kGy}$ in combination with chlorine washing reduced the microbial population by 3 to 4 log colonyforming units/g. Massey et al. (2006), using the bending of lettuce discs under application of a given weight as an index of radiation damage, suggested that lettuce can tolerate 0.6 to $1 \mathrm{kGy}$ radiation. Increased $\mathrm{O}_{2}$ consumption and production of $\mathrm{CO}_{2}$ by the irradiated lettuce were also observed. Foley et al. (2002) found that $0.55 \mathrm{kGy}$ radiation in combination with chlorination caused a $5.4 \mathrm{log}$ reduction of $E$. coli O157:H7 on fresh-cut Iceberg lettuce. Irradiation at this dose did not cause any change in texture or other sensory attributes of lettuce packaged in film bags, indicating that low-dose irradiation can improve both safety and shelf life. Kim et al. (2005) found irradiation at 1.0
kGy reduced Listeria ivanovii to below the limit of detection and did not adversely affect visual quality of lettuce during cold storage in air. In our previous study (Fan and Sokorai, 2002), fresh-cut Iceberg lettuce was irradiated at doses up to $4 \mathrm{kGy}$ in MAP, and it was found that overall visual appearance of lettuce irradiated at 1 or $2 \mathrm{kGy}$ was the best. The better quality is related to high $\mathrm{CO}_{2}$ and low $\mathrm{O}_{2}$ levels observed in packages of the irradiated samples. Warm water treatment $\left(47^{\circ} \mathrm{C}, 3 \mathrm{~min}\right)$ in combination with low-dose $(0.5$ or $1 \mathrm{kGy})$ irradiation helped maintain the sensory quality of fresh-cut lettuce (Fan et al., 2003). Although there have been studies of the quality of irradiated Iceberg lettuce, packaged either in air or with MAP, showing that fresh-cut lettuce can tolerate low-dose irradiation, there have been no quality studies of irradiated fresh-cut Iceberg lettuce in which MAP is directly compared with air storage.

Many factors have to be considered for commercial application of irradiation on lettuce. The availability of irradiation facilities is one of the factors. Ideally, an irradiation facility is located on the site of the fresh-cut processing plant so that fresh-cut lettuce can be irradiated immediately after being packaged. However, currently, there are only a limited number of radiation facilities in the country, and most are located away from major fresh produce packing and processing facilities. For fresh-cut produce to be irradiated, it might have to be shipped to an off-site irradiation facility, which could take 1 to $2 \mathrm{~d}$, depending on the distance, and thereby delaying the time of irradiation. Therefore, the objectives of this study were to study the effects of MAP and delay of irradiation on quality of irradiated fresh-cut lettuce.

\section{Materials and Methods}

Source of lettuce. Iceberg lettuce was provided by a major California lettuce grower. The lettuce was harvested from a single field lot in California and shipped to the Philadelphia Distribution Center in refrigerated trucks, which generally took 3 to $4 \mathrm{~d}$. On receipt, the lettuce was transferred to the USDA-Eastern Regional Research Center and stored overnight at $4{ }^{\circ} \mathrm{C}$ before being treated.

Sample preparation and treatments. Plastic wraps and outer leaves of head lettuce were discarded. Then the lettuce was cored, using a corer (Silver King, Minneapolis, MN), and was cut into 1-inch square pieces using a lettuce cutter (Model SKK2; Silver King). The pieces were randomized by mixing with hands and placed into perforated (air) or non-perforated PD961EZ film bags $(7.7 \pm 0.7 \times 14.0 \pm 0.3 \mathrm{~cm})$ (Cryovac, Duncan, SC; oxygen transmission rate: 6000 to $8000 \mathrm{~mL} / \mathrm{m}^{2} / 24 \mathrm{~h}$ ), each bag containing $150 \mathrm{~g}$ of cut lettuce. The non-perforated film bags were evacuated and flushed with nitrogen using a Multivac C-450 Vacuum Packager (Multivac, Kansas City, MO). The settings for the packaging machine were: vacuum, 200 mbar; evacuation time, $2 \mathrm{~s}$; nitrogen flushing level, $700 \mathrm{mb}$; sealing time, $3 \mathrm{~s}$. The type of film material used and gas 
flushing simulated industry practices. Half of the perforated and non-perforated bags with cut lettuce were then irradiated with $0,0.5$, or $1.0 \mathrm{kGy}$ within $3 \mathrm{~h}$ after cutting, and the remaining bags were irradiated the next day ( $\approx 24 \mathrm{~h}$ ). Sample preparation and treatments are illustrated in Figure 1. This experiment was repeated four times resulting in four replicate bags for each treatment and sampling day. Each replicate of sample was prepared from different batches of lettuce from the same shipment. After irradiation, cut lettuce was stored at $4{ }^{\circ} \mathrm{C}$, and $\mathrm{O}_{2}$ and $\mathrm{CO}_{2}$ levels in the packages, overall appearance, cut edge browning, surface browning, and texture of cut lettuce were measured at 1,7 , and $14 \mathrm{~d}$ of storage.

Irradiation and dosimetry. Lettuce was either untreated $(0 \mathrm{kGy})$ or treated with 0.5 or 1.0 kGy gamma radiation at a dose rate of 0.084 $\mathrm{kGy} / \mathrm{min}$ at $4 \pm 2{ }^{\circ} \mathrm{C}$ using a ${ }^{137} \mathrm{Cs}$ source. The custom-made, self-contained gamma-radiation source (Lockheed Georgia Company, Marietta, GA) has $23{ }^{137} \mathrm{Cs}$ pencils placed in an annular array around a $63.5-\mathrm{cm}$ high stainless steel cylindrical chamber with a $22.9-\mathrm{cm}$ internal diameter. Variations in radiation dose absorption were minimized by placing the samples within a uniform area of the radiation field by irradiating them within a polypropylene container (4-mm wall) to absorb Compton electrons and by using the same geometry for samples during the entire study. Routine dosimetry was performed using 5-mm diameter alanine pellets (Bruker, Inc., Billarna, MA). The pellets were placed into $1.2-\mathrm{mL}$ cryogenic vials (Nalgene, Rochester, NY), and the cryoirradiation. Alanine pellets were read using a Bruker EMS 104 EPR analyzer and compared with a standard curve.

Texture analysis. Texture was determined using the TA-XT2i Texture Analyzer with a $25 \mathrm{~kg}$ load cell (Texture Technologies Corp., Scarsdale, NY) and a Kramer Shear press with five blades. A 25-g sample was placed into the press holder and then the five-blade plunger moved down at $1 \mathrm{~mm} / \mathrm{s}$ to $1 \mathrm{~cm}$ below the bottom of the holder. Forces were recorded every second using the Texture Expert software (Version 1.22; Texture Technologies Corp.). Two readings were made on lettuce samples from each package. There were a total of eight measurements for each treatment. Texture was genic vials were placed with the samples before

expressed as the area $(\mathrm{kg} \times \mathrm{s})$ under the curve of force $(\mathrm{kg})$ versus time (s).

Visual quality evaluation. Each sample was visually examined and rated by three to four judges according to the scoring system developed by Kader et al. (1973) and LopezGalvez et al. (1996). For overall quality, the scales were 9 to $1: 9=$ excellent quality, essentially free from defects, fresh-appearing; 7 = good quality, minor defects; $5=$ fair quality, slightly to moderately objectionable defects, lower limit of sales appeal; $3=$ poor quality, excessive defects; and 1 = extremely poor quality, not usable. Leaf surface browning and edge browning were rated as 1 to 9 with 1 as no browning and 9 as the most severe. Color charts with assigned scores were used to assist the rating of the samples (Kader and Cantwell, 2008).

Headspace atmosphere analysis. Gases in film bags were periodically sampled to determine the levels of $\mathrm{O}_{2}$ and $\mathrm{CO}_{2}$ during storage. To measure the atmosphere, gas in the headspace of bags was withdrawn into an oxygen/ carbon dioxide analyzer (Model 902D; Quantek Instruments, Grafton, MA) through a needle using a built-in pump.

Statistical analysis. The experimental design was a completely randomized design with radiation dose, MAP, and storage times as main factors. Each experiment/treatment was replicated four times. Up to two measurements were analyzed for each replicate of sample. Data were analyzed with SAS Version 9.2 (SAS Institute, Cary, NC). Effects of storage time, radiation dose, and MAP were analyzed using the least significant difference test of the General Linear Model procedure.

\section{Results and Discussion}

$\mathrm{O}_{2}$ and $\mathrm{CO}_{2}$ levels in the packages of cut lettuce after nitrogen flushing were $2.5 \%$ and $1.0 \%$, respectively, measured on the day of packaging. Immediately after irradiation, which was conducted the next day after packaging, $\mathrm{O}_{2}$ and $\mathrm{CO}_{2}$ levels were $0.3 \% \pm 0.6 \%$ and $6.0 \% \pm 0.6 \%$, respectively. During postirradiation storage, $\mathrm{O}_{2}$ levels increased, whereas $\mathrm{CO}_{2}$ level decreased (Fig. 2). At Days 7 and 14 , the effect of irradiation on headspace gas composition was more obvious, particularly on $\mathrm{O}_{2}$ levels. The higher the irradiation dose, the

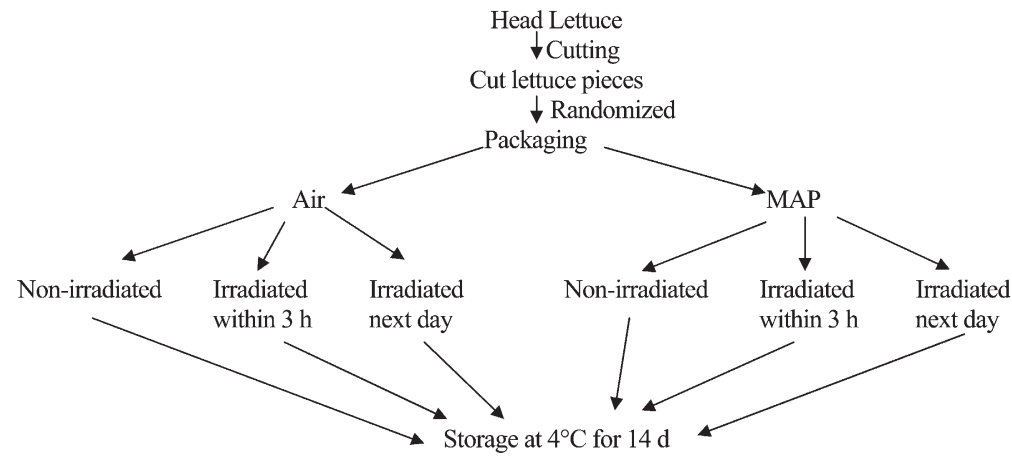

Fig. 1. Schematic diagram for sample preparation and treatments. lower the $\mathrm{O}_{2}$ levels. $\mathrm{O}_{2}$ levels for 0 -, 0.5 -, and $1.0-\mathrm{kGy}$ packages ranged from $5.4 \%$ to $7.5 \%$, $4.1 \%$ to $5.8 \%$, and $3.1 \%$ to $4.2 \%$, respectively, during the latter period of storage. The results suggest that irradiation increased respiration because irradiated lettuce consumed more $\mathrm{O}_{2}$ during storage. Earlier studies have indicated that irradiation increases respiration in fresh fruits and vegetables (Couture et al., 1990; Fan et al., 2003). Delaying application of irradiation on cut lettuce did not have significant $(P>0.05)$ effects on headspace composition during storage (compare Fig. 3 with Fig. 2). Irradiation decreased $\mathrm{O}_{2}$ levels and increased $\mathrm{CO}_{2}$ levels in the MA packages. For example, after $14 \mathrm{~d}$ of storage, $\mathrm{O}_{2} / \mathrm{CO}_{2}$ levels were $6.6 \% / 4.0 \%, 5.4 \% / 4.2 \%$, and $4.1 \% / 4.4 \%$, respectively, for $0-, 0.5-$, and $1.0-\mathrm{kGy}$ samples. Samples stored in perforated bags (air) maintained levels of $0.6 \%$ to $1.2 \% \mathrm{CO}_{2}$ and $20 \%$ to $21 \% \quad \mathrm{O}_{2}$ during storage.

Quality of cut lettuce irradiated immediately (within $3 \mathrm{~h}$ ) after irradiation is presented in Table 1. A score system was used to assess the visual quality of cut lettuce. A score of 5 for overall quality is considered the minimum score required for salability to consumers. One $\mathrm{d}$ after preparation, no significant $(P>0.05)$ difference in overall quality, cut edge, or surface browning was observed between the non-irradiated lettuce $(0 \mathrm{kGy})$ and the two irradiated ( 0.5 and $1.0 \mathrm{kGy})$ samples either in air or in MAP. Cut iceberg lettuce was rated between 8 and 9 in overall quality $1 \mathrm{~d}$ after preparation, suggesting the samples initially were in excellent condition. Seven $d$ after preparation, fresh-cut lettuce packaged in air and irradiated at 0.5 and $1.0 \mathrm{kGy}$ had lower overall quality scores and more severe cut edge and surface browning than the corresponding non-irradiated lettuce. The overall visual quality had a negative correlation with browning on surface or edge, in agreement with an earlier study (Fan et al., 2003). The scores for overall quality of irradiated samples were below 5 after $7 \mathrm{~d}$ of post-irradiation storage, indicating the samples were not marketable. After $14 \mathrm{~d}$ storage, quality of irradiated lettuce stored in air became similar to that of the non-irradiated lettuce, because the nonirradiated sample also deteriorated. Overall quality scores for all samples were low (3.5 to 4). When the samples were stored in MAP, irradiated lettuce had better overall quality and less edge and surface browning than the non-irradiated lettuce at days 7 and 14. For example, the overall quality scores for the 0.5 - and 1.0-kGy samples were 6.9 and 6.5 , respectively, after $14 \mathrm{~d}$ of storage, whereas the control sample had a score of 4.1, an appearance below sales appeal. Considering the lower $\mathrm{O}_{2}$ and high $\mathrm{CO}_{2}$ levels in the MAP of irradiated samples, it appears that the better quality in irradiated samples was the result of lower $\mathrm{O}_{2}$ and higher $\mathrm{CO}_{2}$ in the MAP caused by irradiation-induced respiration. MAP might reduce tissue browning of nonirradiated fresh-cut lettuce, but the beneficial effect of MAP was more profound for irradiated samples than non-irradiated ones. 


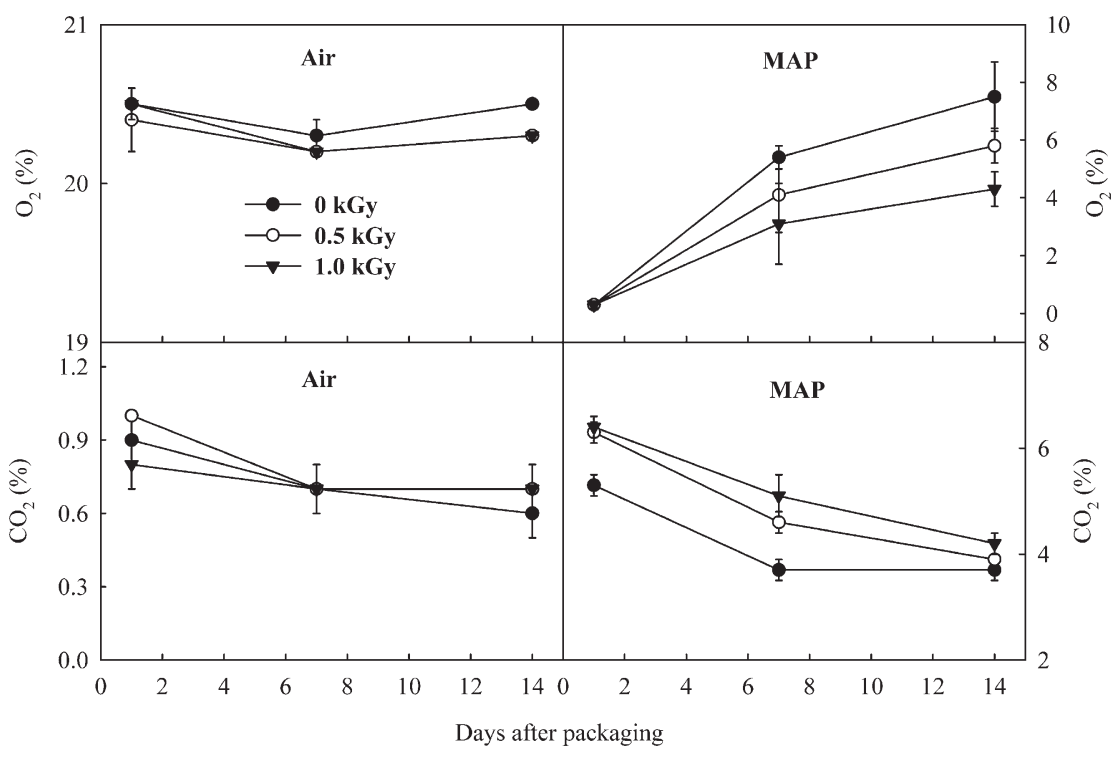

Fig. 2. Changes in headspace composition in packages of fresh-cut Iceberg lettuce during storage at $4{ }^{\circ} \mathrm{C}$. The lettuce was irradiated within $3 \mathrm{~h}$ after preparation. Samples exposed to air were stored in perforated film bags. Vertical bars represent sDs.

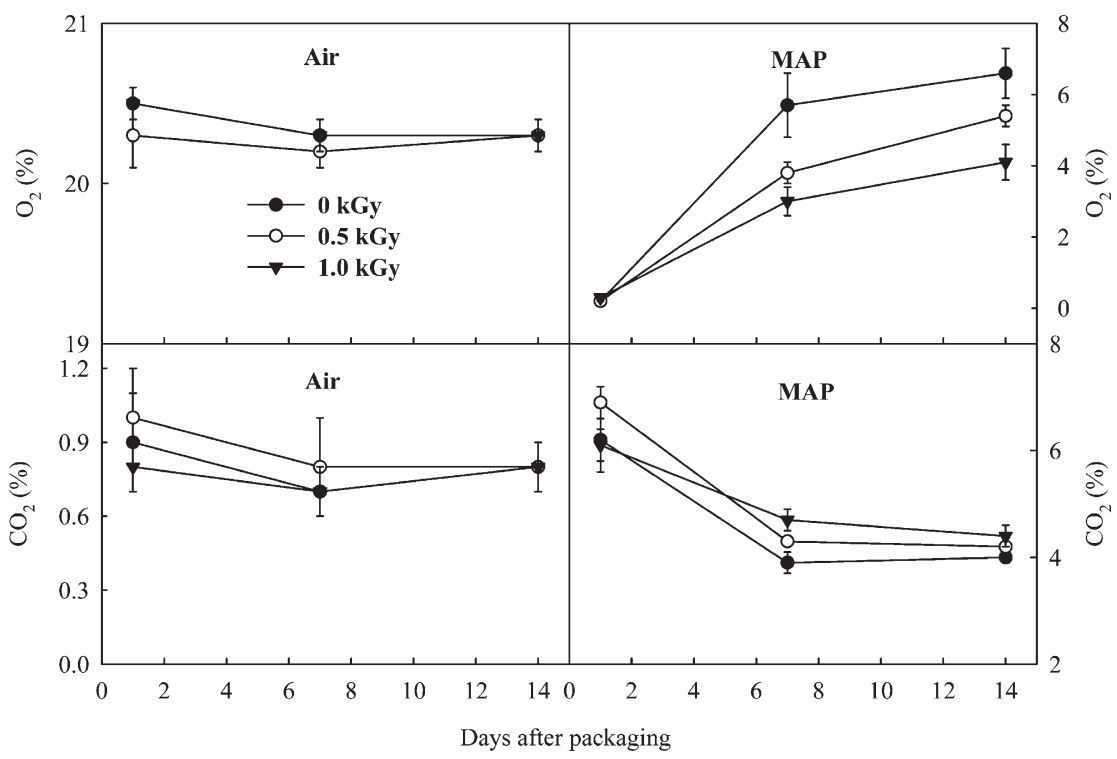

Fig. 3. Changes in headspace composition in packages of fresh-cut Iceberg lettuce during storage at $4{ }^{\circ} \mathrm{C}$. The lettuce pieces were irradiated $1 \mathrm{~d}$ after preparation. Samples exposed to air were stored in perforated film bags. Vertical bars represent SDS.

It is recommended that fresh-cut Iceberg lettuce be stored in $0.5 \%$ to $3 \% \mathrm{O}_{2}$ and $10 \%$ to $15 \% \mathrm{CO}_{2}$ to reduce tissue browning, retain visual quality, and reduce psychrophilic bacterial counts (Gorny, 1997). In our study, the $\mathrm{O}_{2}$ levels in the MAP samples were $0.2 \%$ to $7.5 \%$ and $\mathrm{CO}_{2}$ levels were $3.7 \%$ to $6.9 \% . \mathrm{O}_{2}$ levels for all samples fell into the recommended levels during part of the 14-d storage period, whereas $\mathrm{O}_{2}$ levels $(0.3 \%$ to $4 \%)$ of 1.0 kGy samples were most similar to the recommended levels. However, $\mathrm{CO}_{2}$ levels were below the recommended ranges during the entire storage period. Nevertheless, our study suggested that MAP, even not under the optimal condition, eliminated the tissue browning caused by low-dose irradiation. Tissue brown- lettuce in air had worse visual quality than the non-irradiated control. In addition to MAP, other factors such as irradiation dose, type of lettuce, and growing conditions of lettuce may also have an impact on the response of lettuce to irradiation.

When the application of irradiation after the preparation of fresh-cut lettuce was delayed for $1 \mathrm{~d}$, the quality of lettuce either in air or MAP was unaffected compared with those samples irradiated within $3 \mathrm{~h}$ (Table 1). The scores for overall quality and surface and edge browning were similar between the two sets of samples throughout the $14 \mathrm{~d}$ of storage. When stored in air, irradiated cut-lettuce had lower overall quality scores and higher edge and surface browning after 7 and $14 \mathrm{~d}$ of storage than the non-irradiated control, whereas MAP was effective in inhibiting tissue browning and in improving overall quality of the irradiated fresh-cut lettuce. Similar to samples irradiated immediately after preparation, a non-irradiated control had a overall quality score below 6 after $14 \mathrm{~d}$ of storage, whereas the two corresponding irradiated samples had scores better than 6 . The results suggest that delaying irradiation for 1 $\mathrm{d}$ did not affect the visual quality of lettuce.

Instrumental texture was not significantly affected by irradiation during storage for samples that were irradiated within $3 \mathrm{~h}$ after preparation. It has been shown that irradiation induced softening of some fruits and vegetables (Fan and Sokorai, 2008; Prakash et al., 2000). Fan and Sokorai (2002) did not find significant changes in cut Iceberg lettuce after $1 \mathrm{kGy}$ irradiation, whereas $10 \%$ loss in firmness was observed in cut Romaine lettuce as a result of $0.35 \mathrm{kGy}$ irradiation. Although no significant change in instrumental texture was observed in the present study, lettuce irradiated $1 \mathrm{~d}$ after preparation had $7 \%$ to $11 \%$ lower firmness in average than non-irradiated ones at days 1 and 14 of MAP storage. Perhaps, a higher number of texture measurements is needed to reveal the significance of changes in texture caused by irradiation.

Our results showed that irradiation promoted tissue browning of cut lettuce when stored in air. It is known that irradiation exerts its effect through radiolysis of water, which generates free radicals and other reactive species in water-dominant foods such as lettuce (Simic, 1983). These species and radicals are very reactive and can cause damage on product quality such as tissue browning. Tissue browning is an oxidation process and requires the participation of oxygen (Degl'Innocenti et al., 2005; Ke and Saltveit, 1988, 1989). Our results demonstrated that irradiated cut lettuce should be packaged in MAP to avoid tissue browning resulting from irradiation. It is recommended that fresh-cut lettuce be packaged in MAP (Gorny, 1997; Lopez-Galvez et al., 1996). Commercially, flushing with pre-mixed gases or $\mathrm{N}_{2}$ is commonly used to quickly achieve low $\mathrm{O}_{2}$ in fresh-cut Iceberg lettuce film bags. Therefore, no change from current best industrial practice is needed to apply irradiation on bagged cut lettuce.

Our results suggested that MAP minimized tissue browning caused by irradiation. 


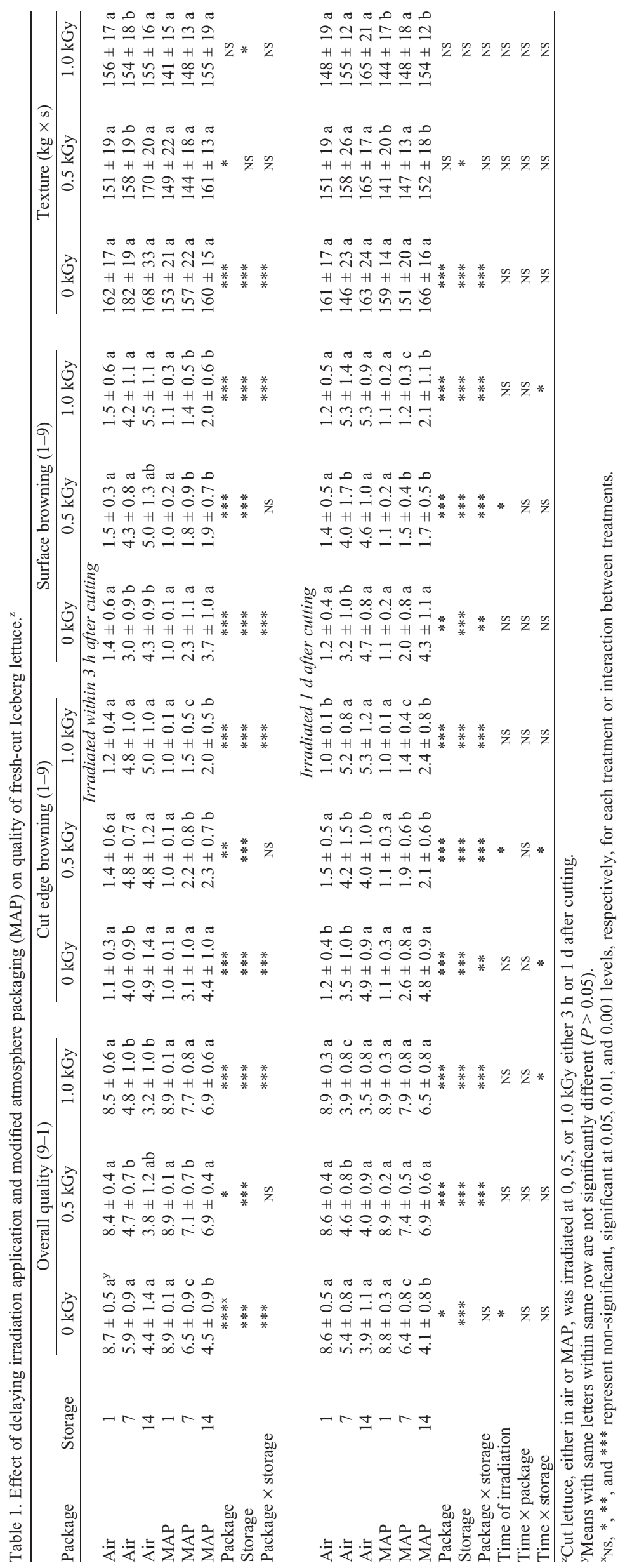

Tissue browning is considered to result from an increase in enzymatic activities such as phenylalanine ammonia lyase, polyphenol oxidase, and peroxidase (Ke and Saltveit, 1989). Phenylalanine ammonia lyase, the key enzyme in the phenylpropanoid pathway, produces phenols; these compounds are then oxidized by polyphenol oxidase and peroxidase, forming quinones, which in turn polymerize to form brown pigments. Although the effects of $\mathrm{O}_{2}$ and $\mathrm{CO}_{2}$ on the enzymes, particularly phenylalanine ammonia lyase, have been studied (Ke and Saltveit, 1989; Lopez-Galvez et al., 1996), little information is available about the response of the enzymes to irradiation in lettuce. It would be interesting to investigate whether irradiation increases activities of any of the enzymes.

As a result of the limited number of radiation facilities available in this country, cut lettuce may need to be transported to an off-site irradiation facility to receive irradiation treatment. As a result, this treatment may be delayed. Our results showed that a 1-d delay did not affect the quality of cut lettuce in MAP. Therefore, irradiation can be applied at a site distant from fresh-cut produce facilities.

In summary, our results demonstrated the importance of MAP in maintaining quality of irradiated Iceberg lettuce. Irradiation promoted tissue browning of cut lettuce when stored in air. However, when cut lettuce was packaged in MAP, irradiated cut lettuce generally had a better appearance than non-irradiated samples. The better quality for the irradiated samples corresponded to the lower $\mathrm{O}_{2}$ levels in the MAP. Furthermore, delaying application of cut lettuce irradiation for $1 \mathrm{~d}$ did not adversely affect product quality, which may allow transportation of cut lettuce to an off-site irradiation facility for treatment.

\section{Literature Cited}

Barth, M., T.R. Hankinson, H. Zhuang, and F. Breidt. 2009. Microbiological spoilage of fruits and vegetables, p. 135-183. In: Sperber, W.H. and M.P. Doyle (eds.). Compendium of the microbiological spoilage of foods and beverages. Springer, New York, NY.

Beaudry, R.M. 1999. Effect of $\mathrm{O}_{2}$ and $\mathrm{CO}_{2}$ partial pressure on selected phenomena affecting fruit and vegetable quality. Postharvest Biol. Technol. 15:293-303.

Couture, R., J. Makhlouf, F. Cheqour, and C. Willemot. 1990. Production of $\mathrm{CO}_{2}$ and $\mathrm{C}_{2} \mathrm{H}_{4}$ after $\gamma$-irradiation of strawberry fruit. J. Food Qual. 13:385-393.

Degl'Innocenti, E., L. Guidi, A. Pardossi, and F. Tognoni. 2005. Biochemical study of leaf browning in minimally processed leaves of lettuce (Lactuca sativa L. var. Acephala). J. Agr. Food Chem. 53:9980-9984.

Fan, X. and K.J.B. Sokorai. 2002. Sensorial and chemical quality of gamma irradiated fresh-cut Iceberg lettuce in modified atmosphere packages. J. Food Prot. 65:1760-1765.

Fan, X. and K.J.B. Sokorai. 2008. Retention of quality and nutritional value of thirteen freshcut vegetables treated with low dose radiation. J. Food Sci. 73:S367-S372.

Fan, X., P.M.A. Toivonen, K.T. Rajkowski, and K.J.B. Sokorai. 2003. Warm water treatment in combination with modified atmosphere packaging 
reduces undesirable effects of irradiation on the quality of fresh-cut Iceberg lettuce. J. Agr. Food Chem. 51:1231-1236.

Foley, D.M., A. Dufour, L. Rodriguez, F. Caporaso, and A. Prakash. 2002. Reduction of Escherichia coli 0157:H7 in shredded Iceberg lettuce by chlorination and gamma irradiation. Radia. Phys. Chem. 63:391-396.

Gorny, J.R. 1997. A summary of CA and MA requirements and recommendations for freshcut (minimally processed) fruits and vegetables. CA 97 Proc. Vol 5, Fresh-cut Fruits and Vegetables and MAP. p. 30-67.

Hagenmaier, R.D. and B.A. Baker. 1997. Low-dose irradiation of cut Iceberg lettuce in modified atmosphere packaging. J. Agr. Food Chem. 45: 2864-2868.

Hodges, M.D. and P.M.A. Toivonen. 2008. Quality of fresh-cut fruits and vegetables as affected by exposure to abiotic stress. Postharvest Biol. Technol. 48:155-162.

Kader, A.A. and M. Cantwell. 2008. Produce quality rating scales and color charts. Post- harvest Technology Research and Information Center, University of California, Davis, CA.

Kader, A.A., W.J. Lipton, and L.L. Morris. 1973 Systems for scoring quality of harvested lettuce. HortScience 8:408-409.

Ke, D. and M.E. Saltveit. 1988. Plant hormone interaction and phenolic metabolism in the regulation of russet spotting in Iceberg lettuce. Plant Physiol. 88:1136-1140.

Ke, D. and M.E. Saltveit. 1989. Regulation of russet spotting, phenolic, metabolism and IAA oxidase by low oxygen in Iceberg lettuce. J. Amer. Soc. Hort. Sci. 114:638-642.

Kim, J., J. Lee, J. Kim, J. Seo, S. Han, H. Chung, and M. Byun. 2005. Effect of gamma irradiation on Listeria ivanovii inoculated to Iceberg lettuce stored at cold temperature. Food Contr. 17:397-401.

Lopez-Galvez, G., M. Saltveit, and M. Cantwell. 1996. The visual quality of minimally processed lettuces stored in air or controlled atmosphere with emphasis on romaine and
Iceberg types. Postharvest Biol. Technol. 8: 179-190.

Massey, L.M., Jr., D.F. Tallman, and Z.I. Kertesz. 2006. Effects of ionizing radiations on plant tissues. V. some effects of gamma radiation on lettuce leaves. J. Food Sci. 26:389-396.

Niemira, B.A. and X. Fan. 2006. Low-dose irradiation of fresh and fresh-cut produce: Safety, sensory and shelf life, p. 169-181. In: Sommers, C.H. and X. Fan (eds.). Food irradiation: Research and technology. Blackwell Publishing and the Institute of Food Technologists, Ames, IA.

Prakash, A., A.R. Guner, F. Caporaso, and D.M. Foley. 2000. Effects of low-dose gamma irradiation on the shelf life and quality characteristics of cut romaine lettuce packaged under modified atmosphere. J. Food Sci. 65:549-553.

Simic, M.G. 1983. Radiation chemistry of watersoluble food components, p. 1-73. In: Josephson, E.S. and M.S. Peterson (eds.). Preservation of food by ionizing radiation. Vol. 2. CRC Press, Boca Raton, FL. 